\title{
AGUA Y MEDIO AMBIENTE EN ESPAÑA: DIAGNÓSTICO Y PERSPECTIVAS DE ALGUNAS LÍNEAS DE ACCIÓN
}

\author{
Miguel Sánchez Fabre y Alfredo Ollero Ojeda \\ Dpto. de Geografía y Ordenación del Territorio, Universidad de Zaragoza
}

\section{RESUMEN}

Teniendo como referente el trascendente papel de las aguas continentales en el medio ambiente, se analiza el cambio de perspectiva que la aplicación de la Directiva Marco Europea del Agua supone en esta relación agua-medioambiente. En este contexto, se abordan algunos de los principales problemas que actualmente afectan al agua y, a través de las masas de agua y los ecosistemas hídricos, al medio ambiente. Finalmente, se plantean diversas iniciativas de gestión y restauración encaminadas a conseguir el buen estado ecológico de las masas de agua continentales. En el artículo queda patente la estrecha interrelación agua-medioambiente, la existencia actualmente en nuestro país de un marco legal que posibilita más que nunca la gestión del agua desde una perspectiva de conservación y mejora del medio ambiente, y la necesidad de que la aplicación de las diferentes normativas conduzca, en la práctica, a la obtención del buen estado ecológico de las masas de agua continental mediante la resolución de diferentes problemas a través de medidas de protección y restauración.

Palabras clave: Agua, medio ambiente, directiva europea marco del agua, presiones sobre el agua, contaminación, afecciones hidromorfológicas, conservación, restauración.

\section{ABSTRACT}

Inland waters play an important role in the environment. The implementation of European Water Framework Directive has caused changes in relationships water-environment. This change of perspective has been analyzed. In this context, some of main problems currently affecting waters, water bodies, water ecosystems and environment are explained. Finally, different management and restoration initiatives for achieving good ecological status of inland water bodies are presented. The paper illustrates the intense water-environment interactions, the existence now in Spain of a better legal framework for water-and-environment management, conservation and improvement, and the need for the achievement of good ecological status by solving problems through protection and restoration measures.

Key words: Water, environment, Water Framework Directive, pressures, water pollution, hydromorphological impacts, conservation, restoration. 


\section{Introducción}

La temática en torno a las interacciones entre el agua y el medio ambiente es enormemente amplia y difícil de acotar. En primer término, se ha procedido a tomar como ámbito de estudio las aguas continentales, descartando las marinas, de propiedades y problemáticas muy diferentes.

\subsection{El agua componente esencial del medio ambiente}

La importancia del agua para el hombre quedó patente desde las primeras civilizaciones. Éstas, denominadas hidráulicas, surgieron a orillas de los grandes ríos (Nilo, Indo, Tigris y Eúfrates...) y sirvieron para que los seres humanos tomaran conciencia de la trascendencia que la presencia del agua suponía para ellos y de las posibilidades que ofrecía su uso. Por ello, iniciaron el desarrollo de diferentes técnicas que favorecían esos usos del agua.

También es reconocido desde tiempos remotos que el agua es un elemento básico del medio natural. El propio Leonardo Da Vinci calificó al agua como motor de la naturaleza. Esta idea ha ido cobrando fuerza con el paso del tiempo, sobre todo a medida que se asocia con el carácter finito del agua y, por tanto, con la necesidad de su conservación y uso racional.

En la actualidad está completamente asumido que el agua es un elemento esencial del Medio Ambiente y que «malgastarla» o reducir su calidad es atentar contra ese medio ambiente y contra el bienestar del hombre. Ahora bien, se asume esa idea tras largos periodos en los que la preocupación esencial por el progreso económico velaba el interés por el medio ambiente. La consecuencia fue su rápido deterioro, que ha afectado esencialmente al agua y a la biodiversidad. La masas de agua se convirtieron en superficies de dilución de elementos tóxicos de variado origen (industria/medio agrario/ámbitos urbanos) y trasladaron su deterioro y contaminación hasta las plantas y los animales.

El problema está detectado, pero también está definida su complejidad. Ésta reside esencialmente en la imposibilidad de separar el agua de su componente social y sus implicaciones económicas. La escala del problema, reconocida y aceptada, es mundial, pero la perspectiva es diferente desde los distintos países: quizás en los desarrollados empieza a pesar significativamente la problemática ambiental, pero en los estados en vías de desarrollo pesa más la necesidad de alcanzar determinados niveles de bienestar a través de la mejora económica que las nefastas consecuencias que a medio o largo plazo conlleva el deterioro del medio ambiente. A nivel de pequeñas comunidades e incluso individual se puede aportar reducción de consumo, disminución de vertidos contaminantes o ahorro energético Pero sólo un cambio de mentalidad tanto individual como colectivo, este último a escala universal, pueden revertir una situación difícil.

Como se ha indicado, el agua es un componente esencial de la naturaleza: la vida en la Tierra depende del agua. Aunque las grandes masas de agua se identifican con los océanos y mares, la afirmación anterior se hace especialmente patente en el ámbito continental, donde la presencia de agua dulce asociada al ciclo hidrológico (Fig. 1) sustenta una enorme variedad de ecosistemas. El agua actúa como motor de la biosfera y suelorocas-relieve-vegetación-agua interactúan continuamente generando esa diversidad de ecosistemas y paisajes. Incluso las propias masas de agua (glaciares, lagos, humedales, ríos) configuran ricos ecosistemas acuáticos. Cuando el hombre se integra en esos ecosistemas suele adquirir un papel clave en su conservación o deterioro ya que cualquier intervención que no sea profundamente respetuosa con el medio ambiente puede romper el equilibrio establecido por la naturaleza. 


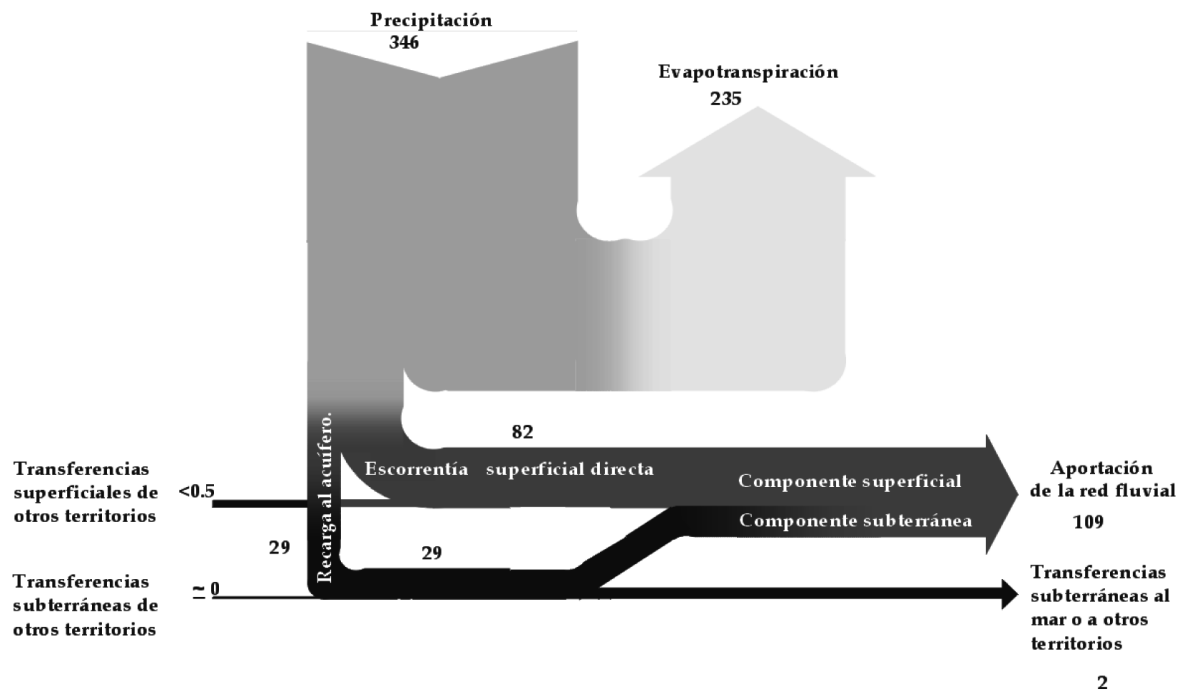

Figura 1. Esquema de los principales flujos de agua $\left(\mathrm{km}^{3} / \mathrm{año}\right)$ en régimen natural para el territorio español (Ministerio de Medio Ambiente, 2000).

\subsection{Agua y medio ambiente, cuestión global}

Diferentes organismos internacionales han abordado los problemas asociados al agua y al medioambiente con ese carácter global, a esa escala del Planeta. Así, desde la UNESCO se organizaron en la década de los 70 diferentes eventos internacionales sobre temas de desarrollo y medio ambiente. Entre ellos, tras la Conferencia de las Naciones Unidas sobre el Medio Ambiente Humano (Estocolmo, 1972), el agua fue tema central en la reunión de Mar del Plata (1977), año en el que también tuvo lugar en Nairobi un evento sobre desertificación. En los años 90 la Conferencia Internacional sobre Medio Ambiente y Desarrollo (Río de Janeiro), que tuvo continuidad con la Cumbre Mundial sobre Desarrollo Sostenible (Johannesburgo, 2002), puso de manifiesto la creciente preocupación de los estados miembros por los temas medioambientales, ya que todos ellos habían creado instituciones para su gestión.

La internacionalización de los problemas relacionados con el agua había dado lugar en 1968 a la Carta Europea del Agua, cuyo objetivo esencial fue una mejora en la gestión de los recursos hídricos tanto en su cantidad como en su calidad. De la mencionada reunión de Mar del Plata surgió el Decenio Internacional del Agua Potable y del Saneamiento Ambiental (1981-1990). A partir de entonces se incrementó el número de conferencias con temáticas relativas al agua, ocupando un papel destacado la Conferencia Internacional sobre el Agua y el Medio Ambiente celebrada en Dublín (1992), cuyos resultados (Declaración de Dublín) no llegaron a ponerse suficientemente en práctica, o la Conferencia Internacional sobre el Agua Dulce (Bonn, 2001). Muy poco antes de la reunión de Bonn, Naciones Unidas hizo pública la Declaración del Milenio de las Naciones Unidas que plantea como objetivo la reducción a la mitad de las personas sin acceso al agua limpia, en el horizonte de 2015. Simultáneamente a las conferencias cobran impulso los foros mundiales del agua (Marrakech, 1997; La Haya, 2000; Kyoto, 2003). 
El balance final de conferencias y foros no es todo lo positivo que cabría esperar, ya que no se han producido grandes avances prácticos en la gestión de los recursos hídricos, ni a escala global mundial, ni a escala nacional (tanto en países desarrollados como en vías de desarrollo). La necesidad de mejorar el aprovechamiento y la calidad de los recursos hídricos sigue vigente, pero todavía hoy la materialización de esta necesidad no es satisfactoria.

Cuando en 2003 la Asamblea General de las Naciones Unidas establece el Decenio Internacional para la Acción «El Agua, fuente de vida», plantea como principal objetivo incrementar el grado de ejecución de los programas y proyectos relacionados con el agua. En ese mismo año el Informe sobre el Desarrollo de los Recursos Hídricos en el Mundo presenta datos alarmantes: 1.100 millones de personas sin acceso a agua potable, 2.400 millones de personas sin acceso a sistemas de saneamiento, en torno a 25.000 muertes diarias por enfermedades transmitidas a través de las aguas, el 50\% de las aguas continentales tienen algún grado de contaminación, se encuentran degradadas el $80 \%$ de las llanuras de inundación, diversos ríos ya no llegan a verter aguas al mar ...

\section{Directiva Marco Europea del Agua}

La Constitución Española de 1978 señala la importancia que el medio ambiente tiene en el desarrollo y en la calidad de vida tanto de los individuos como de la sociedad en que se integran. Así lo expone en diversos apartados de su artículo 45, donde se recoge el derecho a disfrutar de un medio ambiente adecuado y el deber de conservarlo, para lo cual es necesario garantizar un uso racional de todos los recursos naturales.

La Ley de Aguas (29/1985) es el marco básico legal para que el agua, como recurso natural y elemento del medio natural, reciba una correcta gestión. Sus diversas modificaciones (ley 46/1999, real decreto 1/2001, ley 11/2005) han mantenido intactos varios de sus principios esenciales: la consideración de que las aguas superficiales y subterráneas renovables constituyen un recurso unitario subordinado al interés general, la gestión por cuenca hidrográfica, la necesaria planificación hidrológica, la participación de usuarios y administraciones en la gestión del agua, la generalización del Dominio Público Hidráulico, la necesidad de compatibilizar la gestión pública del agua con la ordenación del territorio y la conservación de la naturaleza.

A nivel de la Comunidad Económica Europea los primeros intentos de legislar temas relacionados con el agua se remontan a los años 70 y se asocian a la calidad del agua para diferentes usos. En 1988, durante la reunión celebrada en Frankfurt, se arbitraron algunas medidas dirigidas a mejorar la calidad ecológica de las aguas, normando el vertido de determinados componentes químicos y la emisión de aguas residuales. De una nueva reunión, celebrada esta vez en Sevilla durante 1995, surge la demanda de una reforma de la política comunitaria en materia de Aguas, es decir, de la elaboración de una Directiva Marco.

\subsection{Acento en los aspectos medioambientales del agua}

Tras cinco años de intenso debate tanto de técnicos como de políticos, se publica la Directiva Marco Europea del Agua o Directiva 2000/60/EC (Unión Europea, 2000), impregnada de una nueva concepción de la gestión de los recursos hídricos. Sustituye las estrategias estructuralistas de oferta bajo expectativas de masiva subvención pública por estrategias de gestión de la demanda y conservación de la calidad y la salud de los ecosistemas hídricos. Marca pautas en todos los países de la Unión Europea, entre ellos 
España. Dos son las líneas básicas que vertebran la nueva política de aguas exigida por la Directiva:

- un nuevo enfoque en materia de gestión económica y financiera basada en dos principios económicos - Recuperación Íntegra de Costes y Valor de Oportunidad - , es decir, el precio del agua aumenta y varía (es más caro en zonas deficitarias o en situaciones de escasez) y se convierte, por tanto, en estrategia de gestión de la demanda.

- la exigencia de integrar los valores ambientales desde la perspectiva del desarrollo sostenible, entendiendo que la calidad exigible del agua no es sólo química, sino también biológica y ecológica, lo cual es fundamental para la conservación y recuperación de los ecosistemas ligados al agua.

En esta segunda línea, directamente ligada al tema que nos ocupa, establece la necesidad de aplicar las medidas necesarias para prevenir el deterioro del estado de las aguas superficiales, proteger, mejorar y regenerar todas las masas de agua con objeto de alcanzar un buen estado para las naturales y un buen potencial ecológico para las aguas artificiales y muy modificadas antes del 31 de diciembre del año 2015 (art.4). Los indicadores de calidad para la clasificación del estado ecológico son:

- Indicadores biológicos: fauna bentónica de invertebrados, flora acuática y fauna ictiológica.

- Indicadores hidromorfológicos que afectan a los indicadores biológicos.

- Indicadores químicos y físicoquímicos que afectan a los indicadores biológicos.

Hacia los aspectos medioambientales del agua apuntan gran parte de los ambiciosos objetivos enunciados en la directiva. Entre ellos se pueden diferenciar unos de carácter general y otros que afectan específicamente a un tipo de aguas concretas. Todos tienen como horizonte conseguir el buen estado ecológico de las masas de agua en el año 2015. Entre los objetivos generales destacan:

- Prevenir, proteger y mejorar el estado de los ecosistemas acuáticos así como de los ecosistemas terrestres y humedales en lo relativo a sus necesidades de agua.

- Promover un uso sostenible del agua que suponga la protección a largo plazo de los recursos hídricos disponibles.

- Reducción progresiva de vertidos, emisiones y pérdidas de sustancias prioritarias (señaladas por la propia directiva). Interrupción o supresión gradual de los vertidos, emisiones y pérdidas de sustancias peligrosas prioritarias.

- Reducir progresivamente la contaminación que ya soportan las aguas subterráneas y evitar la llegada a ellas de nuevas fuentes de deterioro.

- Mitigar los efectos de las inundaciones y sequías.

- Garantizar el suministro de agua superficial o subterránea.

- Lograr los objetivos de los acuerdos internacionales, incluidos los relativos al medio ambiente marino.

Estos objetivos generales se ven complementados con diversos objetivos de carácter medioambiental que afectan específicamente a las aguas superficiales, las aguas subterráneas y las zonas protegidas. Entre ellos proteger, mejorar y regenerar todas las masas de agua superficiales y subterráneas con el objeto de alcanzar su buen estado ecológico antes del 2015; también evitar o reducir su contaminación. 
Desde nuestro punto de vista, la Directiva es valiosa y hay que aprovecharla al máximo para desarrollar los cambios que se vienen exigiendo en la gestión del agua y de los territorios fluviales, pero presenta abundantes lagunas y ambigüedades. Una vez más se toman los problemas desde la perspectiva hidrológica-biológica-economicista y se deja en muy segundo término la base geomorfológica y territorial que, desde nuestra experiencia, debería ser clave de toda iniciativa. También falta en la Directiva la componente sociocultural del agua.

\subsection{Las masas de agua continentales en la Directiva Marco del Agua}

El nuevo modelo de gestión hidrológica que propone la Directiva Marco del Agua implica la revisión de alguno de los conceptos habituales en los temas hídricos, así como la aparición de otros que cobran gran trascendencia. En su artículo 2 se definen estos términos que, como no podía ser de otra manera, están estrechamente ligados a los objetivos perseguidos por la Directiva. Así, establecidos los tipos de aguas (continentales, incluyendo superficiales y subterráneas, de transición y costeras), se concreta el significado del concepto masas de agua: concentraciones de agua que se dan en cualquiera de los grandes dominios hídricos del ciclo hidrológico y que se diferencian con claridad de las masas circundantes. Se definen las masas de agua superficial, dentro de las que quedan incluidos los ríos y los lagos, y las masas de agua subterráneas. Además, se contrapone el concepto de masa de agua natural (que no llega a explicitarse) a los de masas de agua artificial y masa de agua muy modificada.

Desde el punto de vista de la división hidrológica del territorio se añade al término básico de cuenca hidrográfica el de demarcación hidrográfica. Finalmente, otra serie de conceptos fundamentales se refieren a los aspectos del uso del agua y del estado ecológico, condiciones medioambientales que éstas presentan.

\subsubsection{Aguas superficiales}

El camino hacia el logro del buen estado ecológico de las aguas superficiales parte de su caracterización. Se trata de identificar, a partir de criterios geográficos e hidrológicos, las diferentes categorías de aguas superficiales: ríos, lagos, aguas de transición, aguas costeras, aguas artificiales y aguas fuertemente modificadas. Identificadas las categorías de masas de aguas hay que establecer en cada una de ellas una tipificación, para determinar lo que la directiva denomina ecotipos.

Estos ecotipos pueden ser definidos por dos sistemas de variables. En el caso de los ríos, el sistema A establece como únicos criterios de tipificación de los cursos fluviales de cada región ecológica (la Península Ibérica queda comprendida en las regiones Ibérico-macaronésica y Pirineos) la altitud, la superficie de la cuenca de alimentación y la geología (Tabla 1). El sistema B incluye como factores obligatorios básicamente los recogidos en el sistema A y como factores optativos diferentes variables de índole topográfica, geomorfológica e hidroclimática (Tabla 2). En general se viene considerando como insuficiente para establecer una buena tipificación el sistema A, juzgando más adecuado el sistema B. Siguiendo el sistema B el CEDEX ha definido 32 tipos de ríos para la Península Ibérica y Baleares (Tabla 3).

Incluso, hay trabajos, como el de Ollero et al. (2004), en los que se realiza la tipificación tomando como base el sistema B pero completándolo con más variables hidrológicas y geomorfológicas que consideran básicas para una adecuada tipificación.

Una vez tipificadas las aguas superficiales, hay que efectuar el análisis de las presiones que diferentes actividades humanas ejercen sobre ellas, pudiendo causar unas consecuencias 
negativas o impacto sobre sus características ambientales. La Directiva Marco destaca la presión e impactos que pueden producir sobre las aguas superficiales los vertidos urbanos e industriales, la contaminación difusa procedente de la agricultura, las extracciones de agua para uso urbano, industrial y agrícola, la presencia de balsas o embalses, las alteraciones de la morfología y dinámica del cauce (construcción de presas, encauzamientos, etc.).

Tabla 1

SISTEMA A DE TIPIFICACIÓN DE RÍOS DE LA DIRECTIVA MARCO EUROPEA

\begin{tabular}{|l|l|}
\hline Tipología fijada & Descriptores \\
\hline Región ecológica & Regiones ecológicas que figuran en el mapa A del anexo XI \\
\hline Típo & $\begin{array}{l}\text { Tipología en función de la altitud } \\
\text { alto }>800 \mathrm{~m} \\
\text { altura media } 200 \text { a } 800 \mathrm{~m} \\
\text { tierras bajas }<200 \mathrm{~m}\end{array}$ \\
& $\begin{array}{l}\text { Tipología según el tamaño en función de la superficie de la } \\
\text { Cuenca de alimentación } \\
\text { pequeño } 10-100 \mathrm{~km}^{2} \\
\text { mediano } 100 \text { a } 1.000 \mathrm{~km}^{2} \\
\text { grande } 1.000 \text { a } 10.000 \mathrm{~km}^{2} \\
\text { muy grande }>10.000 \mathrm{~km}^{2}\end{array}$ \\
& $\begin{array}{l}\text { Geología } \\
\text { Calcáreo } \\
\text { Silíceo } \\
\text { Orgánico }\end{array}$ \\
\hline
\end{tabular}

Tabla 2

SISTEMA B DE TIPIFICACIÓN DE RÍOS DE LA DIRECTIVA MARCO EUROPEA

\begin{tabular}{|l|l|}
\hline Caracterización alternativa & $\begin{array}{l}\text { Factores físicos y químicos que determinan las características del } \\
\text { río o parte del río y, por ende, la estructura y composición de la } \\
\text { comunidad biológica }\end{array}$ \\
\hline Factores obligatorios & $\begin{array}{l}\text { altitud } \\
\text { latitud } \\
\text { longitud } \\
\text { geología } \\
\text { tamaño }\end{array}$ \\
\hline Factores optativos & $\begin{array}{l}\text { distancia desde el nacimiento del río } \\
\text { energía de flujo (función del caudal y de la pendiente) } \\
\text { anchura media del agua } \\
\text { profundidad media del agua } \\
\text { pendiente media del agua } \\
\text { forma y configuración del cauce principal } \\
\text { categoría según la aportación fluvial (caudal) } \\
\text { forma del valle } \\
\text { transporte de sólidos } \\
\text { capacidad de neutralización de ácidos } \\
\text { composición media del sus trato } \\
\text { cloruros } \\
\text { oscilación de la temperatura del aire } \\
\text { temperatura media del aire } \\
\text { precipitaciones }\end{array}$ \\
\hline
\end{tabular}


Tabla 3

TIPOS DE RÍOS PARA LA PENÍNSULA IBÉRICA Y BALEARES. CENTRO DE ESTUDIOS Y EXPERIMENTACIÓN (CEDEX) (ESTRELA, T., COORD., 2004)

\begin{tabular}{|c|l||c|l|}
\hline NÚMERO & \multicolumn{1}{|c||}{ DE NOMINACIÓN } & NÚMERO & DENOMINACIÓN \\
\hline 1 & Ríos de llanuras silíceas del Tajo y Guadiana & 17 & Grandes ejes en ambiente mediterráneo \\
\hline 2 & Ríos de la depresión del G uadalquivir & 18 & Ríos cos teros mediterráneos \\
\hline 3 & Ríos de las penillanuras siliceas de la Meseta Norte & 19 & Ríos Tinto y Odiel \\
\hline 4 & Ríos mineralizados de la Meseta Norte & 20 & Ríos de serranías béticas húmedas \\
\hline 5 & Ríos manchegos & 21 & Ríos cantabro-atlánticos silíceos \\
\hline 6 & Ríos silíceos del piedemonte de Sierra Morena & 22 & Ríos cantabro-atlánticos calcáreos \\
\hline 7 & Ríos mineralizados mediterráneos de baja altitud & 23 & Ríos vas co-pirenaicos \\
\hline 8 & Ríos de la baja montaña mediterránea silicea & 24 & Gargantas de Gredos-Béjar \\
\hline 9 & Ríos mineralizados de baja montña mediterránea & 25 & Ríos de montaña húmeda silícea \\
\hline 10 & Ríos mediterráneos con influencia cárs tica & 26 & Ríos de montaña húmeda calcárea \\
\hline 11 & Ríos de montaña mediterránea silicea & 27 & Ríos de alta montaña \\
\hline 12 & Ríos de montaña mediterránea calcárea & 28 & Ejes fluviales principales cantabro-atlánticos silíceos \\
\hline 13 & Ríos mediterráneos muy mineralizados & 29 & Ejes fluviales principales cantabro-atlánticos calcáreos \\
\hline 14 & Ejes mediterráneos de baja altitud & 30 & Ríos cos teros cántabro-atlánticos \\
\hline 15 & Ejes mediterráneo-continentales poco mineralizados & 31 & Pequeños ejes cantabro-atlánticos silíceos \\
\hline 16 & Ejes mediterráneo-continentales mineralizados & 32 & Pequeños ejes cantabro-atlánticos calcáreos \\
\hline
\end{tabular}

Determinados los tipos de cada categoría de masas de agua superficiales y los impactos que reciben, es el momento de establecer unas condiciones de referencia que serían aquellas que definirían masas de agua en muy buen estado (por ejemplo, Ollero et al., 2004, señalan la masa de agua «río Mascún tramo 2» como el modelo de referencia para el tipo de ríos medios y bajos pirenaicos encajados). La situación de calidad de cada masa de agua se podrá determinar a partir de su grado de alejamiento de estas condiciones de referencia. Tanto el establecimiento de las condiciones de referencia, como la determinación del estado ecológico de cada masa de agua se efectúan a partir del estudio de las características generales del agua, la presencia de contaminantes específicos y el análisis de indicadores biológicos, físico-químicos e hidromorfológicos.

Con la definición del estado ecológico de cada masa de agua, pretende la Directiva Marco disponer de una evaluación previa que determine la situación respecto a los objetivos medioambientales a lograr en 2015 y que permita fijar las medidas para intentar conseguir dichos objetivos. La medición del estado ecológico de las masas de agua deberá ser sometida a un proceso de intercalibración, para asegurar que hay homogeneidad en los criterios de los diferentes países.

\subsubsection{Aguas subterráneas}

También la ruta hacia el logro del buen estado de las aguas subterráneas parte de su caracterización. En España se ha tomado el criterio de asignar como masa de agua subterránea a la Unidad Hidrogeológica. Para determinar la posibilidad de que cada masa de agua subterránea alcance los objetivos medioambientales de la Directiva Marco es preciso un amplio conocimiento de datos hidrológicos, geológicos, edafológicos y relativos a la ubicación y extensión de los acuíferos; también el análisis de las presiones a que están expuestas esas masas de agua, procedentes de la contaminación, de la actividad humana o de las variaciones de nivel (extracción de agua, recarga artificial, etc.); finalmente, el examen de los ríos o humedales a los que alimenten. 
En aquellos casos de masas de agua subterránea que presenten riesgos de no alcanzar los objetivos de calidad propuestos por la Directiva Marco, se debe realizar una caracterización adicional con mayor grado de profundización y detalle.

En estrecha conexión con el espíritu de la directiva aparece, ligado a la presencia de masas de agua subterráneas, el concepto de recurso disponible. No se entiende como tal toda la alimentación de un acuífero, sino que es la diferencia entre la recarga media anual y el flujo necesario para que las masas de agua superficiales conectadas con él consigan sus objetivos medioambientales.

\subsubsection{Zonas protegidas}

Asociada a este proceso de caracterización de diferentes tipos de masas de agua y de definición de su estado de calidad, se encuentra la exigencia de la Directiva Marco para que cada Demarcación Hidrológica elabore un Registro o Catálogo de Zonas Protegidas. Debe incluir todas aquellas que son objeto de alguna figura de protección especial (Red 2000, Zonas de Especial Protección para las Aves, etc.). Además, deben ser consideradas como zonas protegidas: las destinadas a la captación de agua para consumo humano, las designadas para la protección de especies acuáticas, las declaradas de uso recreativo, las áreas sensibles a nutrientes, las dedicadas a protección de hábitats y especies cuando la calidad del agua sea un factor decisivo para conseguir esta protección.

\section{Problemática actual}

Se estima que en España hay 1.621 ríos catalogados y unos 2.500 humedales. Por su parte, los acuíferos, considerando tanto los grandes acuíferos como los de carácter local, ocupan más de tres cuartas partes de la superficie del país. Unas y otras masas de agua se alimentan recogiendo aproximadamente el 30\% de las precipitaciones registradas.

Tanto la definición de modelos de referencia como el establecimiento de diferentes zonas de protección sirven para evidenciar el buen estado de diversas masas de agua en España, así como de los ecosistemas asociados a ellas, generando paisajes de gran valor y espectacularidad. Pero frente a ello, se constata también la presencia de un buen número de masas de agua cuya degradación hace que el objetivo de buena calidad marcado para el horizonte del 2015 por la Directiva Marco del Agua, esté muy lejos y el riesgo de no conseguirlo sea grande.

\subsection{Presiones, contaminación y control de la calidad}

Frente a masas de agua en buen estado, más o menos cercanas a su modelo de referencia, otras se encuentran muy afectadas por diferentes presiones (Figs. 2 y 3):

- Fuentes puntuales. Identificadas con vertidos orgánicos urbanos, vertidos industriales y vertidos de piscifactorías. Conducen hasta las aguas superficiales sustancias peligrosas, incrementan la presencia de sólidos en suspensión, provocan alteraciones orgánicas y de oxigenación, aportan nutrientes y modificaciones a los ecosistemas, pueden determinar cambios en la fauna piscícola y en la cadena trófica. Si se cumple con la legislación vigente no debiera afectar a las masas de agua subterráneas, ya que está prohibido cualquier vertido puntual que pueda llegar hasta algún acuífero.

- Fuentes difusas. Pueden proceder de zonas industriales, extracciones mineras o escombreras, pero sobre todo están ligadas a la actividad agrícola que puede trasladar, hasta masas de agua superficiales y subterráneas, tanto nitrógeno como otros componentes químicos de fertilizantes, plaguicidas, herbicidas y fungicidas. 
- Extracciones de agua. Alcanzan en diversos casos el volumen suficiente para producir disminuciones significativas del caudal de los ríos o marcados descensos del nivel freático. Pueden resultar especialmente preocupantes cuando las extracciones afectan a un acuífero, superando el ritmo de extracción al de recarga. El uso al que se destina la mayor parte de esta agua es la agricultura.

- Regulaciones de caudal. Afectan a las masas de agua superficial, esencialmente los ríos, pudiendo producir, si la capacidad de almacenamiento de agua en embalses es elevada, cambios en el régimen fluvial. A su vez, estos cambios en el régimen pueden provocar afecciones en diferentes ecosistemas fluviales. Puesto que la regulación se va incrementando hacia los tramos medios y bajos de los sistemas fluviales, es en ellos donde la alteración del régimen puede ser mayor.

- Morfológicas. Azudes, obras de encauzamiento y extracciones de áridos producen cambios en la dinámica fluvial y alteran la morfología de los cauces fluviales y sus márgenes, reduciendo o eliminando su naturalidad.

- Otras incidencias: especies de peces alóctonas. La introducción en algunas masas de agua superficial de peces alóctonos puede conducir a cambios muy significativos en la fauna piscícola e incluso a la desaparición de las especies autóctonas.

- Usos del suelo. Asociadas a determinados usos del suelo pueden darse circunstancias con incidencia en las masas de agua. Así, por ejemplo, los incendios son fuente de contaminación difusa tanto para las aguas como para la atmósfera. La deforestación, por su parte, provoca un incremento de la erosión y el arrastre de sólidos hasta las masas superficiales de agua.

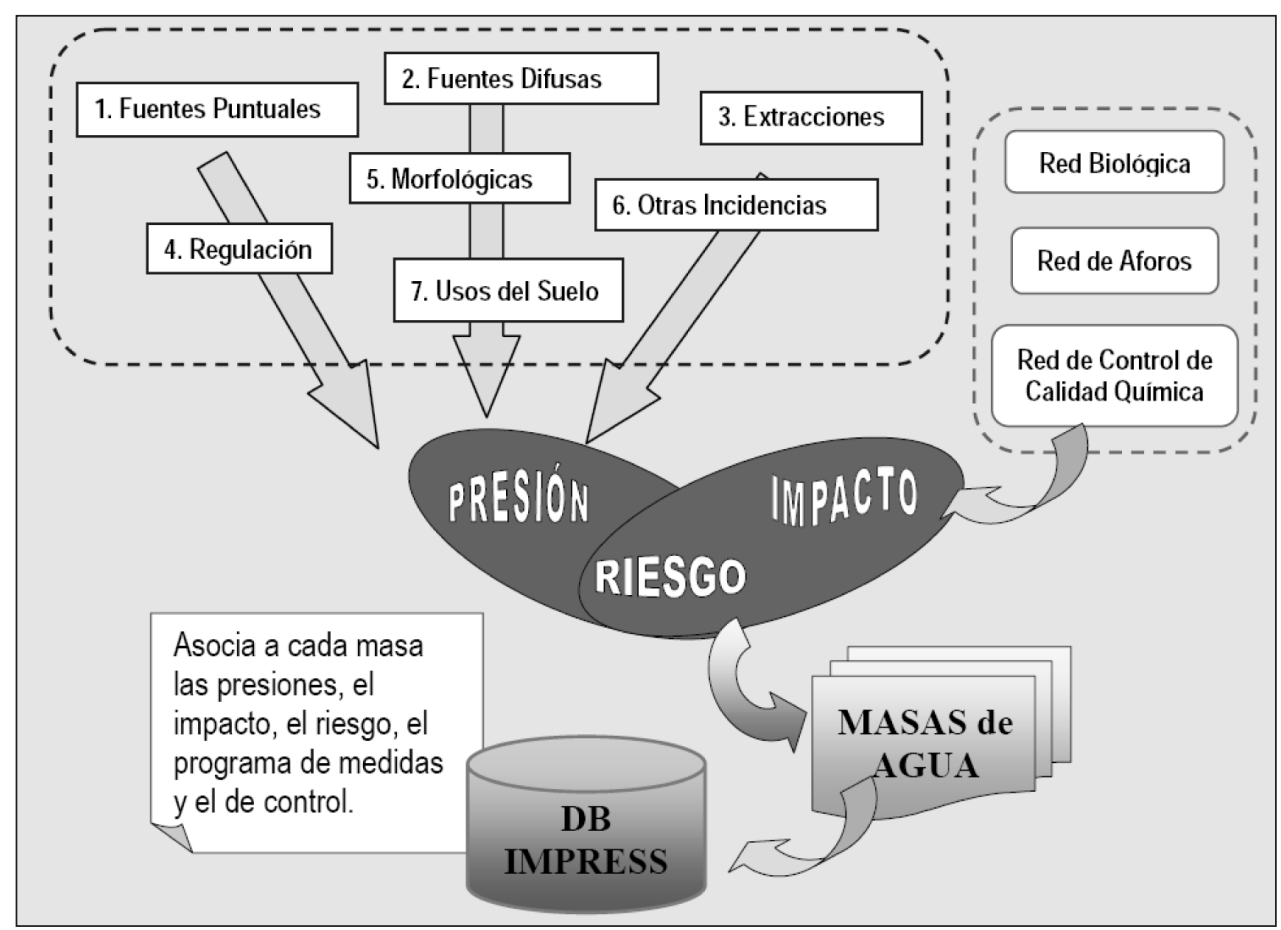

FIGURA 2. Organización de la información IMPRESS Estrela, T. (coord., 2004). 
- Intrusiones marinas. Generalmente asociadas a sobreexplotaciones de acuíferos, producen la salinización de aguas dulces subterráneas.

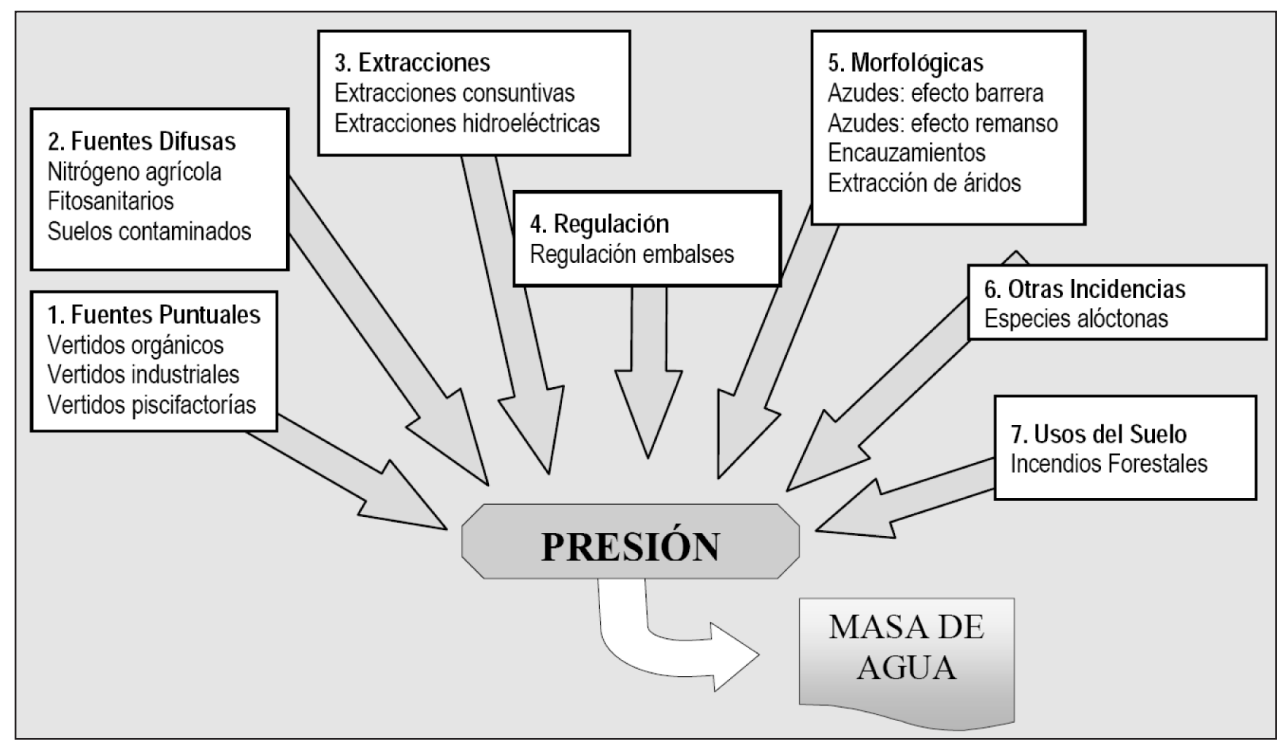

Figura 3. Principales presiones identificadas en la Demarcación del Júcar. Estrela, T. (coord., 2004).

Un problema básico, el mejor evaluado y el que más medios cuenta para ser paliado, es la contaminación del agua, que puede ser básicamente de tres tipos: la que afecta a las propiedades físicas del agua (color, olor, sabor, turbidez, espumas), la contaminación química y la contaminación microbiológica (asociada a vertidos de aguas residuales sin depurar) (Nombela et al. 2004). Las principales fuentes o fuerzas motrices de esa contaminación son la población, la agricultura y la actividad industrial.

En la actualidad existen en España sistemas de control tanto de la cantidad como de la calidad de las aguas. El control de la cantidad se efectúa a través de la Red Oficial de Estaciones de Aforo (ROEA), que incluye más de 700 puntos de medida en ríos, embalses y canales en cuencas de competencia estatal, los Sistemas Automáticos de Información Hidrológica (SAIH), ya implantados en la mayor parte de las Demarcaciones hidrológicas, y la Red piezométrica de aguas subterráneas, con casi 3.000 puntos de control de los niveles piezométricos en acuíferos. También las cuencas de competencia autonómica disponen de redes de medida relativamente similares.

La calidad de las aguas es controlada a través de las estaciones de la Red Integrada de Calidad de las Aguas (ICA), la Red de Estaciones Automáticas de Alerta (SAICA), la reciente Red de control biológico, la Red de Control de Calidad de la Aguas Subterráneas, la Red de Control de Calidad de las Aguas de Baño y la Red Nacional de Control de Radiactividad Ambiental.

- La red ICA cuenta con más de 2.000 estaciones en las diferentes Confederaciones con competencias estatales. Incluye todas las redes tradicionales de vigilancia de la 
calidad de las aguas superficiales: COCA (Control Oficial de la Calidad del Agua), funcional desde 1962, COAS (Control de la Calidad de las Aguas destinadas a Abastecimientos), COPI (Control de Calidad de Aguas destinadas a Vida Piscícola) y RCSP (Control de Sustancias Peligrosas).

- La red SAICA reúne unas 200 estaciones en zonas de usos críticos o focos de importante contaminación. Una de sus principales aportaciones es la toma de datos continua y en tiempo real.

- La Red de Control Biológico está impulsada por la Directiva Marco europea del Agua. Incluye el territorio con competencias estatales y las cuencas internas de Cataluña y el País Vasco. Sus mecanismos de control se intentan incorporar a los puntos de control de la red ICA, siendo registros de la presencia en el agua de macroinvertebrados, diatomeas, peces y macrófitas.

- Red de Control de Calidad de Aguas Subterráneas. En sus más de 1.400 puntos de control se vigilan 30 parámetros físico-químicos.

- Red de Control de Calidad de las Aguas de Baño. Tiene como objetivo la observación del cumplimiento de los criterios marcados por las directivas comunitarias para las aguas de baño.

- Red Nacional de Control de Radiactividad Ambiental. Desde 1978 el Consejo Superior de Seguridad Nuclear realiza un seguimiento de varios parámetros radiológicos en el agua.

En la actualidad, varias de estas redes se están adaptando para poder cumplir diferentes programas de control de calidad de las masas de agua, surgidos al amparo de la Directiva Marco europea del Agua y que afectan a todo el territorio español, sea su gestión estatal o autonómica (Tablas 4 y 5).

Junto a estos programas de control de la calidad de las aguas, otras medidas relativas al uso del agua pueden contribuir a una mejora del medio ambiente. Aparece entre ellas la eficiencia en el uso, cualquiera que éste sea. La modernización de los sistemas de riego junto a la racionalización del consumo en los hogares y la mejora de las redes de conducción urbana, se presentan como las claves de ese incremento de la eficiencia en el uso del agua. A este respecto hay actuaciones, a muy diferentes escalas territoriales, que marcan la dirección a seguir: Plan Nacional de Regadíos, gestión urbana del agua en ciudades como Sevilla y Zaragoza, etc.

También es muy evidente el impacto en el medio ambiente de la depuración de aguas y vertidos. Las legislaciones española, a partir del Plan Nacional de Saneamiento y Depuración, y europea han creado en los últimos años un marco adecuado para que se articulen grandes avances prácticos en el terreno de la depuración. Como consecuencia se han construido un buen número de depuradoras tanto en zonas de vertidos industriales como urbanos. La relación entre la depuración y la calidad de las aguas de ríos, lagos y acuíferos es directa $\mathrm{y}$ tiene un reflejo casi inmediato.

Los resultados de mejora de la calidad medioambiental todavía son mayores si la depuración se asocia a la reutilización del agua. Esto supone una menor detracción de recursos hídricos de los sistemas naturales y una disponibilidad de agua para determinados usos en ámbitos deficitarios, donde además mediante la reutilización de agua se puede reservar la de mayor calidad para usos muy concretos. Los posibles usos para los que puede reutilizarse el agua dependen del tipo de tratamiento realizado en las plantas depuradoras. El más generalizado es el riego agrícola, junto al riego de jardines y calles. Hay otros muchos como varios urbanos (lavado de coches, instalaciones de aire acondicionado, etc.), el in- 
Tabla 4

PROGRAMAS DE CONTROL DE AGUAS SUPERFICIALES DERIVADOS DE LA DIRECTIVA MARCO EUROPEA DEL AGUA (VILLANUEVA Y SÁINZ, 2008)

\begin{tabular}{|c|c|c|c|}
\hline Nombre & $\begin{array}{l}\text { Númer o de } \\
\text { estaciones }\end{array}$ & Tipo de contr oles & Justificación \\
\hline $\begin{array}{l}\text { Programa de control de } \\
\text { vigilancia de las masas de agua } \\
\text { superficiales }\end{array}$ & $\begin{array}{l}1.533 \text { en ríos } \\
304 \text { en lagos }\end{array}$ & $\begin{array}{l}\text { Biológicos } \\
\text { Hidromorfológicos } \\
\text { Físico-químicos }\end{array}$ & $\begin{array}{l}\text { Ofrecer una visión del estado de } \\
\text { las masas de agua de todo el país } \\
\text { y evaluar cambios a largo plazo }\end{array}$ \\
\hline $\begin{array}{l}\text { Programa de control operativo } \\
\text { de las masas de agua } \\
\text { superficiales }\end{array}$ & $\begin{array}{l}1.165 \text { en ríos } \\
128 \text { en lagos } \\
\end{array}$ & $\begin{array}{l}\text { Elementos más sensibles al } \\
\text { tipo de presión que afecta a } \\
\text { la masa de agua }\end{array}$ & $\begin{array}{l}\text { Determinar las masas de agua } \\
\text { que pudieran no cumplir los } \\
\text { objetivos de calidad y valorar los } \\
\text { cambios al aplicar diferentes } \\
\text { programas }\end{array}$ \\
\hline $\begin{array}{l}\text { Red de control de las zonas } \\
\text { protegidas de las masas de agua } \\
\text { superficiales }\end{array}$ & $\begin{array}{l}428 \text { en ríos } \\
115 \text { en lagos }\end{array}$ & $\begin{array}{l}\text { Físico-químicos } \\
\text { Microbiológicos }\end{array}$ & $\begin{array}{l}\text { Zonas protegidas que abastecen } \\
\text { agua para consumo humano }\end{array}$ \\
\hline Redes de referencia & $\begin{array}{l}229 \text { en ríos } \\
8 \text { en lagos } \\
\text { (aproximación: no } \\
\text { son cifras } \\
\text { definitivas) } \\
\end{array}$ & $\begin{array}{l}\text { Biológicos } \\
\text { Hidromorfológicos } \\
\text { Físico-químicos }\end{array}$ & $\begin{array}{l}\text { I dentificación condiciones de } \\
\text { referencia del estado ecológico } \\
\text { de las aguas, para diferentes } \\
\text { tipos de masas de agua }\end{array}$ \\
\hline Red de intercalibración & & $\begin{array}{l}\text { Diferentes elementos } \\
\text { intercalibrados según } \\
\text { categoría de ríos y lagos }\end{array}$ & $\begin{array}{l}\text { Obligación de intercalibración } \\
\text { para que los resultados obtenidos } \\
\text { en cada país, respecto al estado } \\
\text { ecológico de las masas de agua, } \\
\text { sean comparables }\end{array}$ \\
\hline $\begin{array}{l}\text { Programa de control de } \\
\text { investigación de las masas de } \\
\text { agua superficiales }\end{array}$ & & & $\begin{array}{l}\text { Determinar las causas del } \\
\text { incumplimiento de la calidad } \\
\text { ecológica marcada para una } \\
\text { masa de agua }\end{array}$ \\
\hline $\begin{array}{l}\text { Otros: Red de control de calidad } \\
\text { de A guas destinadas a V ida } \\
\text { Piscícola. Red de Contaro de } \\
\text { Calidad de Aguas destinadas a } \\
\text { A bastecimientos }\end{array}$ & & & $\begin{array}{l}\text { Coexisten temporal mente estas } \\
\text { antiguas redes con los nuevos } \\
\text { programas }\end{array}$ \\
\hline
\end{tabular}

dustrial (refrigeración, alimentación de calderas, etc.), inyección en el terreno (recarga de acuíferos, restricción de la intrusión salina, etc.), el medioambiental (regeneración de lagos y humedales, incremento de caudales, etc.) y el recreativo (láminas de agua ornamentales, fabricación de nieve artificial, etc.), pero todos ellos tienen un mayor número de restricciones por los «efectos secundarios» que pueden producir. Por ello, está normado el nivel de calidad mínima de las aguas reutilizadas para ser empleadas en cada uso.

Aunque la reutilización del agua en nuestro país se centra fundamentalmente en las zonas costeras mediterráneas y sur-atlánticas y en los archipiélagos de Baleares y Canarias, no se descartan en otros ámbitos más húmedos. Un buen ejemplo es el Plan de reutilización integral de Vitoria-Gasteiz, uno de los primeros referentes de reutilización de agua en España, con evidentes beneficios en el abastecimiento, la producción hidroeléctrica y el incremento de tierras de regadío.

También la desalación de agua puede contribuir a la mejora medioambiental en la medida en la que pueda minimizar la sobreexplotación de determinados acuíferos y sistemas fluviales. El volumen de agua desalada en algunas zonas de nuestro país se ha incrementado de modo espectacular en los últimos años, estando todavía por precisar el costo de producción y ajustar determinados problemas de eliminación de residuos (Prats y Melgarejo, 2006). 
Tabla 5

PROGRAMAS DE CONTROL DE AGUAS SUBTERRÁNEAS DERIVADOS DE LA DIRECTIVA MARCO EUROPEA DEL AGUA (VILLANUEVA Y SÁINZ, 2008)

\begin{tabular}{|l|l|l|l|}
\hline \multicolumn{1}{|c|}{ Nombre } & \multicolumn{1}{|c|}{$\begin{array}{c}\text { Número de } \\
\text { estaciones }\end{array}$} & Tipo de controles & \multicolumn{1}{c|}{ Justificación } \\
\hline $\begin{array}{l}\text { Programa de control de } \\
\text { vigilancia de las masas de agua } \\
\text { subterráneas }\end{array}$ & 2.637 & Físico-químicos & $\begin{array}{l}\text { Evaluar el impacto en las } \\
\text { diferentes masas de agua } \\
\text { subterráneas }\end{array}$ \\
\hline $\begin{array}{l}\text { Programa de control operativo } \\
\text { de las masas de agua } \\
\text { subterráneas }\end{array}$ & 1.310 & $\begin{array}{l}\text { Determinar las masas de agua } \\
\text { que pudieran no cumplir los } \\
\text { objetivos de calidad y valorar los } \\
\text { cambios al aplicar diferentes } \\
\text { programas }\end{array}$ \\
\hline $\begin{array}{l}\text { Red de control de las zonas } \\
\text { protegidas de las masas de agua } \\
\text { subterráneas }\end{array}$ & 582 & $\begin{array}{l}\text { Elementos más sensibles de presión que afecta a a de agua } \\
\text { la masa de }\end{array}$ & \\
\hline
\end{tabular}

Finalmente, un elemento clave para el mantenimiento de la calidad del agua y sus ecosistemas es la planificación hidrológica. En nuestro país la base de esta planificación la constituyen los Planes Hidrológicos de cuenca, responsabilidad de las Demarcaciones hidrográficas, y el Plan Hidrológico Nacional, del que está a cargo el Ministerio de Medio Ambiente y Medio Rural y Marino. Los Planes de cuenca aprobados por Real decreto en 1998 incluyen entre sus contenidos: inventario de recursos hídricos, usos y demandas existentes y previsibles, criterios de prioridad y compatibilidad de usos, asignación y reserva de recursos para necesidades actuales y futuras, características básicas de calidad de las aguas y de ordenación de vertidos, normas básicas sobre mejoras y transformaciones en regadío, perímetros de protección y medidas para la conservación, planes hidrológicoforestales y conservación de suelos, directrices para recarga y protección de acuíferos, infraestructuras básicas, criterios de evaluación de los aprovechamientos energéticos y criterios sobre asuntos relacionados con las inundaciones. Estos Planes de cuenca están en proceso de sustitución por los Planes hidrológicos de cuenca, cuyo ámbito territorial es la demarcación hidrográfica y cuyos contenidos están definidos en el Texto Refundido de la Ley de Aguas y desarrollados en el Reglamento de Planificación: descripción general de la demarcación hidrográfica, descripción general de los usos y presiones, zonas protegidas, redes de control, objetivos ambientales, análisis económico del uso del agua y programas de medidas. En estos nuevos contenidos se aprecia claramente la transposición de las líneas básicas de la Directiva Marco Europea del Agua a la Ley de Aguas.

\subsection{Afecciones hidromorfológicas sobre los sistemas naturales asociados al agua}

Los ríos, barrancos y ramblas añaden a los problemas de contaminación hídrica unas muy destacadas y generalizadas alteraciones hidrogeomorfológicas, causadas por el creciente consumo humano de agua, sedimentos y espacio a lo largo de los siempre apetecibles ejes fluviales. En el caso de lagunas y otros humedales, muchos fueron desecados a lo largo del siglo XX para ganar terreno al cultivo o incluso como puntos de vertido de escombros. 
En los cursos fluviales los impactos geomorfológicos son muy importantes y extendidos, pero son mucho menos evaluados y mucho más difíciles de solucionar que la calidad hidrológica. Las afecciones geomorfológicas más destacables son los procesos de incisión originados aguas abajo de los embalses por desnaturalización hidrológica y por reducción de flujos sedimentarios, la eliminación de la dinámica lateral de los cauces a causa de las defensas, la reducción funcional de la llanura de inundación por defensas e infraestructuras, las alteraciones de la forma del cauce, fondo y márgenes y el deterioro de las riberas provocados por canalizaciones, dragados e invasiones del espacio del río.

Estas alteraciones geomorfológicas son muy graves y extendidas e incluso están produciendo modificaciones en las tipologías fluviales. Destaca, por ejemplo, la tendencia a la desaparición de los cursos trenzados (braided) de gravas. Esta destrucción antrópica de las dinámicas geomorfológicas fluviales, acelerada en las últimas décadas, se ha desarrollado por desprecio a los valores geomorfológicos o por desconocimiento de estas dinámicas, de forma inconsciente o bien interesada. Cada vez se ejecutan más actuaciones directas en cauces y riberas relacionadas con los crecientes procesos de urbanización, actuaciones que son cada vez más agresivas. Además son afecciones no valoradas ni evaluadas (Ollero, 2008), ya que en la inmensa mayoría de los proyectos ni siquiera se contempla el impacto geomorfológico como variable a evaluar. No se observa ningún tipo de preocupación generalizada por esta problemática en responsables de la gestión hídrica y territorial. Se constata un amplio desconocimiento de la dinámica geomorfológica de los sistemas fluviales, paralelo a un consolidado desprecio social por los cauces de gravas, por los lechos secos o por las orillas inestables.

Pese a esta situación, desde el ámbito científico-técnico han ido surgiendo diferentes metodologías de evaluación que incluyen parámetros hidromorfológicos, en el contexto de la aplicación de la Directiva 2000/60/CE: el índice QBR (Qualitat del Bosc de Ribera) propuesto por Munné et al., (1998), el IHF (Índice del Hábitat Fluvial) desarrollado por Pardo et al. (2002), el RQI (Riparian Quality Index) de González del Tánago et al. (2006), el más estrictamente geomorfológico IHG (Índice Hidrogeomorfológico) propuesto por Ollero et al. (2007) o el IAR (Índice de Alteración de Ramblas) de Suárez y Vidal-Abarca (2008).

\subsection{Los últimos glaciares}

Por su singularidad en el territorio español y su enorme valor ambiental, no puede plantearse el panorama del agua y medio ambiente actual en nuestro país sin una referencia al fenómeno glaciar. Los escasos glaciares que sobreviven en la Península Ibérica son los más meridionales de Europa occidental, se localizan en los Pirineos oscenses y constituyen sistemas naturales de gran valor por su carácter relicto, así como excelentes indicadores del cambio global. Todos ellos se encuentran protegidos por el Gobierno de Aragón con la figura de Monumento Natural. Por su difícil accesibilidad son masas de hielo que sufren escasas presiones, pero son muy sensibles a los eventos meteorológicos y a los balances anuales de temperaturas y precipitaciones.

Desde hace algunas décadas se vienen desarrollando trabajos de seguimiento que evalúan el espesor de la capa de hielo, las modificaciones en las superficies glaciares y la temporalidad y volumen de los procesos de fusión (Cancer et al., 2001a,b; Chueca y Julián, 2002; Chueca et al., 2007). El Ministerio de Medio Ambiente y Medio Rural y Marino desde el programa ERHIN, que cuantifica los recursos hídricos procedentes de la nieve acumulada en alta montaña, también realiza campañas periódicas de reconocimiento y control en los frentes de diferentes aparatos glaciares. En líneas generales puede afirmarse que el retroceso glaciar pirenaico ha sido continuo desde 1880 y se ha acelerado desde 1970 por el 
aumento térmico y la reducción de la innivación, que han incidido en los débiles procesos de compactación de las capas de nieve inferiores. En 1894 el cartógrafo Schrader midió 1.779 hectáreas de superficie glaciar en la vertiente surpirenaica, de las que en la actualidad quedan menos de 350 ha. Desde 1970 la mitad de los aparatos glaciares pirenaicos ha evolucionado hacia morfologías de menor entidad (heleros) o bien ha desaparecido. Hoy quedan solo 13 glaciares.

Sin embargo, en la primera década del siglo XXI esta tendencia regresiva parece haberse frenado, registrándose una alternancia de balances anuales positivos y negativos que se han compensado. Observaciones visuales recientes en algunos aparatos glaciares muestran superficies glaciadas similares a las observadas en 1998 ó 2000. Esta inflexión puede ser un simple paréntesis temporal en el marco del inevitable cambio global, pero también puede indicar que la pronosticada como inminente (un siglo a lo sumo) desaparición de los últimos glaciares puede ser, al menos, más lenta de lo previsto.

\section{Iniciativas de protección y restauración}

En la situación actual la gestión ambiental debe encaminarse por dos procesos complementarios: la protección o conservación de los sistemas naturales en mejor estado y la restauración o rehabilitación de los que se encuentran alterados.

\subsection{Mecanismos de conservación}

En el caso de los humedales lacustres y palustres se ha avanzado mucho en su conservación, especialmente desde la firma en 1971 del convenio de Ramsar, que entró en vigor en 1975. Desde entonces muchos humedales han sido protegidos y restaurados en nuestro país, contando con el apoyo político y social. De hecho, España fue el primer país en contar con una de las estrategias exigidas en Ramsar: el Plan Estratégico Español para la Conservación y Uso Racional de los Humedales, aprobado en octubre de 1999.

No puede decirse lo mismo de ríos, barrancos y ramblas, sobre los que las presiones e intereses son de mucha mayor intensidad. En estos casos los mecanismos de conservación son escasos, no se han podido apoyar en principios claros y casi siempre constituyen fuente de conflictos. Sería necesaria una importante labor desde las confederaciones hidrográficas, que deberían reducir su muy desarrollada acción promotora de actuaciones impactantes en cauces e incrementar su hasta ahora escasa acción de vigilancia ambiental.

Los Lugares de Importancia Comunitaria (LIC) son ecosistemas catalogados para su protección prioritaria, integrados en la red Natura 2000, a raíz de la Directiva 92/43/CE. Las comunidades autónomas han trabajado y propuesto las redes de LICs. Se aprecia que un elevado porcentaje de ellos están estrechamente relacionados con la presencia de masas de agua superficiales, fundamentalmente ríos y lagos (Fig. 4). No obstante, esta red de LICs asociados a sistemas fluviales es en muchos casos insuficiente y presenta carencias de continuidad. En la actualidad la figura LIC no está suponiendo todavía una protección efectiva. Tan sólo a algunas actuaciones fluviales se les exige el procedimiento de evaluación de impacto ambiental si afectan a tramos LIC.

Desde la Directiva del Agua 2000/60/CE se fomenta la conservación de las masas de agua en muy buen estado ecológico. En este sentido, y a propuesta de la Ley 11/2005, de 22 de junio, por la que se modifica la Ley 10/2001, de 5 de julio, del Plan Hidrológico Nacional, surgió la figura de Reservas Naturales Fluviales. El Ministerio de Medio Ambiente encargó un trabajo de catalogación llevado a cabo por el Área de Ingeniería Ambiental del CEDEX desde 2006. Con esta red de Reservas se pretende alcanzar la protección y 


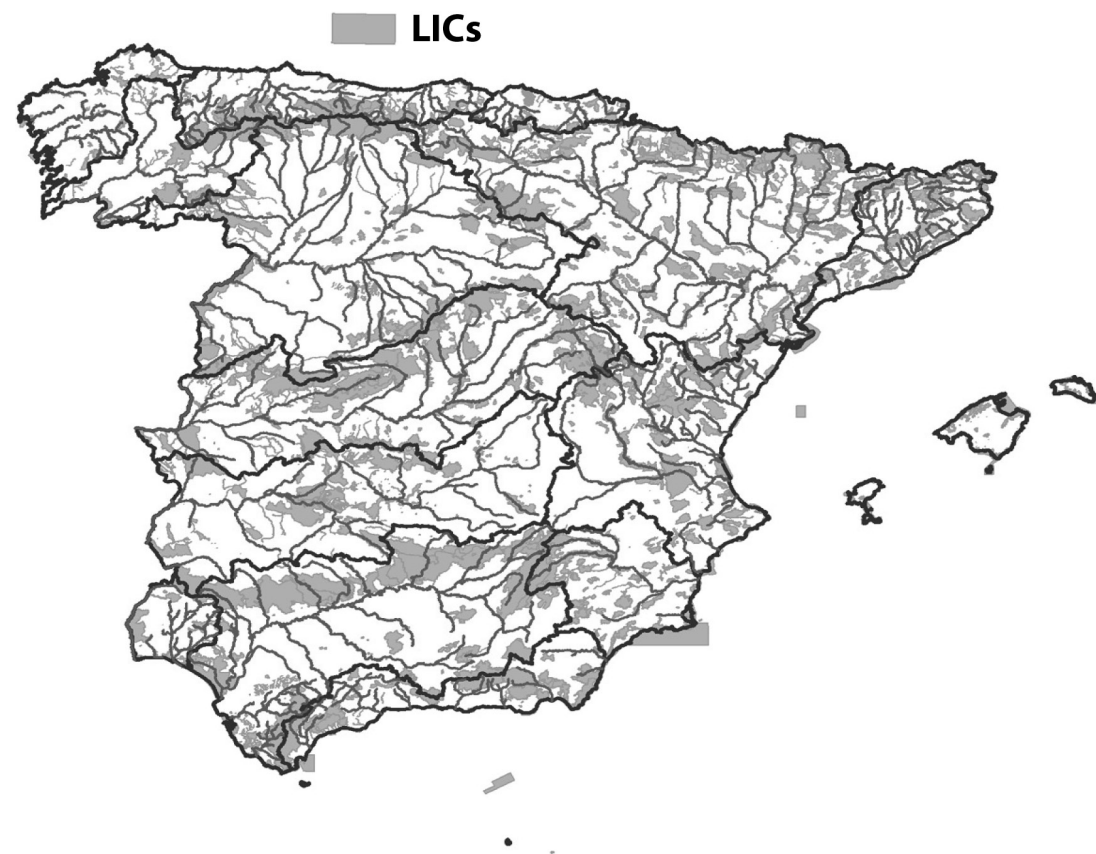

Figura 4. Distribución de los Lugares de Importancia Comunitaria en España, excepto Canarias (manchas de tono gris). Fuente: Sistema Integrado de Información del Agua. Ministerio de Medio Ambiente y Medio Rural y Marino. Elaboración propia.

conservación de los tramos fluviales aún no alterados por la acción del hombre en las distintas cuencas hidrográficas españolas, el mantenimiento de un número amplio de tramos fluviales que sean representativos de la diversidad biológica que aún es posible encontrar en los diferentes tipos de ecosistemas fluviales, y que permitan su utilización como tramos de referencia en el ámbito de los objetivos de la Directiva 2000/60/CE, y la selección de aquellos tramos fluviales que merecen un especial esfuerzo de recuperación con el fin de alcanzar una verdadera red de corredores biológicos de índole fluvial, capaces de vertebrar los espacios protegidos en la actualidad por ser parte de la Red Natura 2000.

Una primera propuesta se concluyó en 2008. Se basó en criterios relacionados con la alteración hidrogeomorfológica de los ríos, y con la estructura y composición de la vegetación riparia. Sin embargo, se consideraron también otros aspectos, como la ausencia de presiones de origen humano, el buen estado físico-químico de las aguas, y el nivel de alteración de las comunidades biológicas propias del río (Berastegi et al., 2008). Después del análisis de todos estos elementos, mediante trabajos de campo y la recopilación y estudio de los materiales cartográficos y bibliográficos existentes, se procedió a la selección y preparación de los tramos en mejor estado de conservación, dando lugar a la creación de una primera propuesta del Catálogo Nacional de Reservas Fluviales. Lo conforman 357 tramos fluviales como Reservas Fluviales y 98 tramos como Paisajes Fluviales, alcanzando unos $2.900 \mathrm{~km}$ de longitud total las primeras y unos $1.200 \mathrm{~km}$ los segundos. Este Catálogo inicial fue presentado como informe y también en formato de guía visual interactiva (aún 
sin publicar). Esta información se encuentra ahora en proceso de debate por las confederaciones. Éstas deben incluir las reservas fluviales en los planes hidrológicos de cuenca, pero en algunos casos están siendo muy reticentes, ya que la figura implicará la imposibilidad de ejecutar actuaciones sobre los tramos protegidos, por lo que se está restringiendo el número de reservas.

A estas iniciativas hay que añadir la presencia de figuras de protección sobre tramos fluviales en diferentes comunidades autónomas desde los años ochenta. Se trata generalmente de reservas naturales muy restringidas espacialmente, pequeños espacios con bosques de ribera relevantes. Cuentan con programas de conservación definidos en sus PORN y PRUG. Se trata, en suma, de las únicas protecciones efectivas de cursos fluviales y los resultados son en general positivos, pero se trata de experiencias muy puntuales y desconectadas entre sí, que no generan una red ni han logrado objetivos relacionados con el principio de continuidad fluvial.

Continuidad longitudinal y conectividad transversal y vertical son algunos de los objetivos de una propuesta muy demandada y con creciente importancia internacional, los territorios fluviales o espacios de movilidad fluvial (Ollero, 2007; Ollero y Elso, 2007). Consiste en la protección o «devolución al río» de espacios fluviales anchos y continuos, mediante limitación de usos y retirada o retroceso de defensas, con objetivos de mejora ambiental y de recuperación del papel laminador de las llanuras de inundación, papel reclamado por la Directiva 2007/60/CE de riesgos de inundación. Esta iniciativa del territorio fluvial en absoluto se está pudiendo implantar en España, aunque ha sido propuesta en numerosos estudios científico-técnicos, en especial en ríos de llanura. En la actualidad se está estableciendo una red europea de trabajo por iniciativa francesa, partiendo de las experiencias desarrolladas en las cuencas del Loira y del Ródano, así como en los programas de acciones en el Rhin y en el Danubio y afluentes.

Esta iniciativa del territorio fluvial está muy relacionada con la delimitación del Dominio Público Hidráulico, figura clave en la legislación hidrológica española que, sin embargo, sólo ha sido puesta en práctica en una reducida longitud de cursos fluviales (proyecto LINDE). Las propias administraciones son reacias a acelerar el proceso ante la respuesta social que implican las expropiaciones que deberían exigirse.

En suma, aunque hay ideas y propuestas de futuro interesantes, el panorama actual de la protección efectiva de los cursos fluviales españoles puede calificarse de deficiente. Por ello, desde muchos colectivos se demandan propuestas legislativas e iniciativas de gestión y ordenación que protejan definitivamente los ríos de mayor naturalidad y valor ecológico y que mejoren el estado de los tramos afectados por presiones e impactos.

\subsection{Restauración de ríos y humedales}

La gestión ambiental del agua y de los sistemas naturales implica un conjunto de medidas y procesos de carácter preventivo, corrector y recuperador. El más avanzado de estos procesos es la restauración, no siempre posible a causa de la intensidad y extensión de las presiones e impactos. Y es que la restauración es el último paso, el más avanzado, un paso viable y factible en situaciones de gestión ambiental sostenible, pero difícil o imposible en sociedades incapaces de renunciar a su imparable consumo de recursos. En estos casos la restauración es muy urgente y necesaria, pero resulta inaplicable por la imposibilidad de eliminar, o siquiera reducir, las presiones. En estos modelos económicamente «avanzados» y ambientalmente insostenibles puede aspirarse a lo sumo a la rehabilitación, al logro de pequeñas mejoras, o a la protección de pequeños enclaves inconexos y relictos. Así, en líneas generales, se han producido algunos éxitos puntuales 
de conservación más restauración en pequeños humedales endorreicos, pero no se han podido llevar a cabo procesos de auténtica restauración en ríos, sistemas mucho más complejos y difíciles de recuperar.

Es precisamente en estas sociedades de consumismo y grave deterioro ambiental donde han surgido preocupaciones e iniciativas científicas y sociales de restauración, que lamentablemente se ven obligadas a quedarse en la teoría o las buenas intenciones. Desde el ecologismo y las ciencias ambientales se ha desarrollado el sentimiento de la belleza de lo natural y la responsabilidad de su conservación (González del Tánago y García de Jalón, 2007). Es un deber conservar y mejorar nuestro entorno para traspasarlo a las generaciones futuras en buen estado. De acuerdo con Soar y Thorne (2001), tenemos incluso la obligación moral de renaturalizar los ambientes dañados por una larga historia de insensibles obras de ingeniería. Se ha comenzado a apreciar, incluso estéticamente, los sistemas naturales activos, dinámicos, heterogéneos, complejos, inestables, temporales, fluctuantes, irregulares, imprevistos, en continuo cambio. Se pretende recuperar la estética de lo cambiante y salvaje, rechazando la domesticación y simplificación propugnadas por la sociedad del consumo y el «bienestar».

Así, la restauración ambiental se ha convertido en un gran reto de nuestro tiempo, pero se quedará en quimera irrealizable a no ser que los poderes económicos y la voluntad política acepten un profundo cambio de mentalidades en lo territorial y ambiental hacia la reducción del consumo y hacia la sostenibilidad. Es también curioso constatar que en estas sociedades «avanzadas» haya surgido un importante yacimiento de empleo y nicho de mercado en torno a la «restauración», así como un motivo de prestigio y factor de localización para las «áreas restauradas» (Gómez Orea, 2004). En ningún caso se trata de auténtica restauración, sino de prácticas de maquillaje que forman parte muchas veces de procesos urbanísticos y especulativos. Es el marketing de la palabra «restauración», utilizada en demasía, con absoluta falta de propiedad y con objetivos no ambientales (Elliot, 1982; Katz, 2003).

\subsubsection{Sobre el concepto de restauración}

¿Qué es entonces la auténtica restauración? Restaurar es restablecer o recuperar un sistema natural, devolviéndole sus procesos naturales (y todas las interacciones entre sus elementos y con otros sistemas), su estructura (componentes y flujos en toda su complejidad y diversidad), sus funciones (dentro del sistema Tierra), su territorio (el espacio propio y continuo, que debe ocupar para desarrollar todos sus procesos y funciones), su dinámica natural a lo largo del tiempo y su resiliencia (fortaleza frente a futuros impactos, capacidad de auto-regulación y auto-recuperación), a partir de la eliminación de los impactos que lo degradaban y a lo largo de un proceso prolongado en el tiempo, hasta alcanzar un funcionamiento natural y autosostenible. La auténtica restauración es, por tanto, auto-restauración. El sistema debe ser capaz de recuperarse solo progresivamente, a lo largo de un proceso, desde el momento en que se eliminen los impactos.

En la situación actual de los sistemas naturales y de su gestión, la restauración es toda una revolución. Porque hay dos requisitos básicos para restaurar, y la sociedad debe estar dispuesta a asumirlos: a) eliminar o reducir al mínimo las causas del deterioro; b) reconsiderar las actividades humanas que generaron esas causas.

La restauración debe lograr naturalidad, funcionalidad, dinamismo, complejidad y diversidad, no belleza ni recreo ni estabilidad, ni simplemente cumplir con la legalidad. Restaurar no es estabilizar, revegetar, ajardinar, urbanizar, maquillar o camuflar. Por ejemplo, la restauración paisajística no es restauración, ya que se centra en el aspecto del sistema 
natural o de alguno de sus elementos, y no en la funcionalidad o dinámica del mismo; no persigue un objetivo natural. Las técnicas de bioingeniería o ingeniería natural, cada vez más extendidas, tampoco deben asociarse con la auténtica restauración, ya que generalmente buscan objetivos estéticos o de estabilización.

Por tanto, hay una restauración auténtica y muchas posibles mejoras parciales, a las que conviene no llamar restauración, sino rehabilitación, restablecimiento, remediación, mitigación, naturalización, creación, acondicionamiento, adecuación, etc., según sus caracteres. No existe todavía un consenso generalizado sobre la amplitud de todos estos conceptos, pero parece que frente a la auténtica pero muchas veces utópica restauración se va consolidando el concepto de rehabilitación, como el conjunto de medidas factibles para la mejora, sin poder llegarse a la recuperación total. Esta rehabilitación no hay que verla de forma negativa por no ser estricta y auténtica restauración, ya que también es muy necesaria y positiva para los sistemas naturales y hay que valorar el esfuerzo que supone, porque tampoco es nada sencilla.

\subsubsection{Restauración de humedales}

Siendo la tipología de humedales muy amplia, los más frecuentemente integrados en programas de restauración son las albuferas y lagunas costeras, los lagos y lagunas endorreicas, cauces fluviales desconectados, manantiales y salinas. La restauración de humedales es una de las líneas más potentes y tradicionales de la gestión ambiental en España y es el ámbito en el que más proyectos pueden considerarse de auténtica restauración. Ello se debe a que se cuenta con figuras de protección consolidadas y con mucho apoyo de la investigación científica, y en general se trata de sistemas naturales menos complejos que ríos o costas, por lo que la restauración es relativamente sencilla, rápida y visible. Paralelamente en otro ámbito de mejora ambiental, también es frecuente la creación de humedales como habitual mecanismo de recuperación de minas y graveras.

Se considera que en España se llegaron a perder un $60 \%$ de los humedales en las últimas décadas (Canicio et al., 2005). Muchos sufrieron importantes mermas en su superficie y funciones al ser desecados y transformados, con el fin de destinar estas zonas al cultivo agrícola, expansión urbanística, o bien como resultado de políticas encaminadas a mejorar las condiciones sanitarias eliminando focos de enfermedades, como el paludismo o la malaria. Este era uno de los objetivos, por ejemplo, en la instauración de las confederaciones hidrográficas.

Las bases que hay que considerar para la restauración de humedales son la hidrología en régimen natural, la relación con cuenca hidrográfica y acuíferos, la calidad de las aguas, la geomorfología y dinámica espacio-temporal, la biodiversidad, la sensibilización social, la eliminación de especies exóticas y el seguimiento científico (Montes et al., 2007). En muchos casos es factible la restauración pasiva, eliminando simplemente los factores causantes de la degradación. Si esas presiones eran puntuales puede ser suficiente con prohibición de usos o cercado del humedal. Las estrategias pasivas permiten la regeneración natural de las comunidades de plantas, la recolonización natural de la fauna y el restablecimiento de la hidrología y suelos. Cuando hay que actuar se utilizan técnicas de bioingeniería o soluciones naturales, tratando de producir el mínimo impacto posible al emplear materiales rápidamente integrados que imiten o se asemejen a formas naturales, y utilización de especies nativas. Se trata de impulsar procesos naturales para que la restauración sea autosostenible. Es fundamental la creación de una aureola de amortiguación (buffer) en torno al humedal, generalmente con vegetación permanente para atrapar y controlar contaminantes, asegurando la calidad de agua, el hábitat y otros beneficios ambientales. Igualmente son oportunas las estrategias para controlar la eutrofización (biorremediación, biomanipulación, filtros verdes, etc.). 
Entre otros muchos ejemplos de restauración de humedales pueden destacarse los gestionados recientemente desde el Ministerio de Medio Ambiente y Medio Rural y Marino: Salburúa (Álava), laguna Larga de Villacañas (Toledo), laguna de La Nava (Palencia) o Saladar de Jandía (Fuerteventura).

\subsubsection{Principios de la restauración fluvial}

La auténtica restauración fluvial debería ser fundamentalmente auto-restauración hidrogeomorfológica y requeriría caudales naturales incluyendo crecidas, sedimentos movilizables, espacio (territorio fluvial) para el desarrollo de la dinámica natural, eliminar obstáculos longitudinales y transversales, y tiempo para la auto-recuperación. Sin embargo, esta auténtica restauración es prácticamente imposible, ya que los ríos, torrentes, barrancos y ramblas sufren numerosas presiones e impactos en toda su cuenca, la mayor parte de las cuales no se pueden eliminar. Si fuera posible eliminar todos los impactos (presas, defensas, canalizaciones), la restauración fluvial sería rápida y efectiva, ya que unas pocas crecidas serían suficientes para recuperar todo el funcionamiento natural.

Las principales dificultades para restaurar ríos derivan de la enorme complejidad de los sistemas fluviales, de la imposibilidad de restaurar grandes impactos (embalses), de la ausencia de antecedentes (en nuestro país y en ámbitos mediterráneos) que puedan servir como modelo, y de las enormes inercias sociales y conflictos administrativos, con ausencia de voluntad política y social para restaurar la dinámica fluvial, de manera que es necesario y urgente un cambio profundo de mentalidad. La sociedad actual consume mucha agua y también sedimentos (áridos) y ha ocupado buena parte de los territorios fluviales, intensos procesos de urbanización y especulación que provocan un continuo incremento en el deterioro fluvial. Además, la correcta restauración está muy alejada de las actuales demandas sociales: seguridad, estabilidad, parques fluviales, domesticación de las riberas, modelos urbanos frente a naturalidad (gravas y vegetación espontánea son sucias), moda de los escollerados, etc.

La restauración fluvial se apoyaría en medidas como la prohibición de dragados y «limpiezas», la apertura o derribo de presas para que pasen los sedimentos, recuperación de caudales naturales y sobre todo las crecidas dinamizadoras, eliminación de defensas para permitir la erosión de las orillas y la removilización de sedimentos, devolución al cauce de su espacio de movilidad, dejar que se generen nuevas superficies de sedimentos que la vegetación irá colonizando, dejar que las riberas se vayan estructurando y convirtiendo en complejos mosaicos de ambientes y hábitats de biodiversidad a partir de la dinámica hidrogeomorfológica, permitiendo que regresen valiosas especies autóctonas, etc. En suma, se trataría de liberar al sistema fluvial de presiones para que pueda volver a ejercer sus funciones: que el río vuelva a funcionar como un río.

Frente a todo ello se encuentra el pobre sucedáneo que la mayoría de las veces se ejecuta como «marketing de restauración»: estabilizaciones de orillas, aun cuando se haga con técnicas blandas de ingeniería natural, revegetaciones, plantaciones de chopos, ajardinamiento y urbanización de márgenes, maquillaje de dragados o escolleras, ampliaciones de sección de desagüe, etc.

\subsubsection{La Estrategia Nacional de Restauración de Ríos}

Iniciativa del entonces Ministerio de Medio Ambiente, iniciada en 2006, contó con diferentes mesas de trabajo (agricultura, urbanización, regulación de caudales, alteraciones morfológicas y especies exóticas) en las que se consensuaron principios generales de la 
restauración y cuyos documentos pueden descargarse desde la página web del Ministerio. Se preparó también una guía metodológica (González del Tánago y García de Jalón, 2007). La estrategia ha incluido también un destacable Programa de Voluntariado en ríos. Recientemente cuenta con un boletín divulgativo semestral titulado Sauce.

El logro de los objetivos de la estrategia pretende llegar hasta la mejora del conocimiento sobre el funcionamiento y la dinámica natural de los ríos españoles por parte de los técnicos encargados de su gestión, la mayor percepción de la relación entre el río y su cuenca vertiente, y entre unos tramos y otros en el continuo fluvial, valorando el efecto acumulativo de las intervenciones en el tiempo y en el espacio, la formación más actual y transdisciplinar de los equipos y personas que en la actualidad redactan y llevan a cabo los proyectos de intervención en los ríos, los nuevos enfoques para una planificación del aprovechamiento sostenible de los recursos hídricos y la conservación de los ecosistemas acuáticos. También persigue el aumento de la percepción social de los problemas asociados a los ríos relacionados con las presiones existentes y su efecto acumulativo a escala de cuenca vertiente y paisaje fluvial y la mayor participación pública en los debates y toma de decisiones sobre la gestión de los cauces y llanuras de inundación y las actividades y presiones que pueden influir en su funcionamiento ecológico.

La ENRR ha contribuido a sensibilizar sobre la necesidad de recuperar los ríos, pero ha perdido el empuje con que se inició, en buena medida desde que se han ido poniendo en práctica algunos proyectos. Éstos en su mayoría no responden a los principios teóricos desarrollados en las mesas de trabajo de la Estrategia, sino que se quedan en actuaciones convencionales de rehabilitación.

\subsubsection{El Centro Ibérico de Restauración Fluvial (CIREF)}

Con ámbito en España y Portugal, forma parte del European Centre for River Restoration (ECRR, fundado en Dinamarca en 1999). El CIREF se constituyó en junio de 2009 y en el verano de 2010 contaba con 105 socios. Los fines de esta asociación sin ánimo de lucro son los siguientes:

- Fomentar la participación, así como apoyar y asesorar en actividades e iniciativas públicas y privadas encaminadas a proteger, conservar y restaurar los espacios fluviales.

- Establecer, mantener relaciones y obtener la adecuada representación en los organismos e instituciones de carácter público y privado que incidan en este campo de actuación, colaborando con ellos en cuanto sea beneficioso para los sistemas fluviales.

- Difundir y defender los valores de los ecosistemas fluviales, colaborar en la lucha contra su degradación por contaminación, dragado, encauzamiento, regulación, embalses y ocupación de sus riberas y zonas inundables.

- Promover internacionalmente proyectos u otras actividades de cooperación al desarrollo sostenible, compatible con la conservación y restauración de ecosistemas fluviales.

- Promover el intercambio de información entre los diferentes profesionales que desarrollan proyectos de restauración fluvial o que participan a nivel conceptual en su desarrollo, con el fin de mejorar el nivel técnico de los mismos.

Se trabaja en varias comisiones de trabajo: sensibilización y divulgación, comunicación (boletín y página web: cirefluvial.com), base de datos de actuaciones de restauración, eventos, publicaciones (notas técnicas) e investigación, etc. En la actualidad el CIREF constituye un avanzado marco de trabajo para el debate, el fomento y el seguimiento de la restauración fluvial. 


\section{Conclusiones}

Hay una relación directa entre el estado del agua, elemento principal del medio natural y esencial para la vida del hombre, y el del medio ambiente. La componente social y económica del agua ha hecho que habitualmente no se priorice esta vertiente medioambiental sino su uso, pudiendo caer en sobreexplotación y deterioro del recurso.

La interacción agua/medioambiente se produce a muy diferentes escalas, incluida la planetaria. Por tanto, es necesaria la internacionalización de determinados problemas del agua. Reuniones y programas internacionales no han conseguido, hasta el momento, solventar no sólo cuestiones medioambientales asociadas al agua, sino cuestiones básicas como el acceso de millones de personas al agua y al saneamiento.

La ley de aguas española y sus posteriores modificaciones, junto con la Directiva Marco Europea del Agua, han creado un marco legal donde se resaltan los aspectos medioambientales del agua. En la Directiva se plantean diversos objetivos dirigidos conjuntamente a conseguir el buen estado ecológico de las diferentes masas de agua en el año 2015. Corresponde, ahora, a los gestores llevar a cabo las acciones que permitan materializar esos objetivos de marcado carácter medioambiental; en segundo plano, los individuos deben apoyar con su actitud diaria ese caminar hacia el logro del buen estado ecológico.

Las masas de agua en España reciben diferentes tipos de presiones: vertidos orgánicos urbanos, industriales y de piscifactorías, vertidos difusos agrícolas, industriales o mineros, extracciones de agua, regulaciones de caudal, modificaciones morfológicas, alteraciones de la fauna piscícola, presiones derivadas de los usos del suelo (incendios, erosión) e intrusiones marinas. Varias de estas presiones derivan en una contaminación de las aguas que afectan a sus propiedades físicas, químicas y características microbiológicas.

Las consecuencias de estas presiones y el nivel de contaminación de las masas de agua son controlados en España a través de diferentes redes de estaciones de medida de diferentes parámetros. Los más destacados son la Red Integrada de Calidad de las Aguas (ICA), la Red de Estaciones Automáticas de Alerta (SAICA) y Red de Control de Calidad de Aguas Subterráneas. Las variaciones en la cantidad de agua se aprecian a través de los datos registrados en las estaciones de aforo de la Red Oficial de Estaciones de Aforo (ROEA) y los Sistemas Automáticos de Información Hidrológica (SAIH); estos últimos como las estaciones de la red SAICA ofrecen datos en tiempo real.

Los cursos fluviales pueden verse afectados, además de por la contaminación de las aguas, por destacadas y generalizadas alteraciones hidrogeomorfológicas, producidas por el creciente consumo humano de agua, sedimentos y territorio. Las principales afecciones geomorfológicos son la incisión aguas abajo de los embalses, la eliminación de la dinámica lateral, la limitación del funcionamiento de la llanura de inundación, la alteración de la forma de los cauces, su fondo y sus márgenes, y el deterioro de las riberas. Estas afecciones a la dinámica fluvial se han incrementado en las últimas décadas, principalmente asociadas a procesos de urbanización, sin que se hayan realizado evaluaciones de dichos efectos antes de llevar a cabo los procesos urbanísticos. Quizás el desconocimiento de la propia dinámica fluvial y su importancia paisajística y medioambiental ha estado en la base de esta forma de proceder. En un intento de paliar esta situación, diferentes grupos de técnicos e investigadores han elaborado índices para evaluar estas afecciones hidrogeomorfológicas.

Los glaciares del territorio español, de gran singularidad y valor ambiental, muestran desde finales del siglo XIX un continuo retroceso. Éste parece haberse frenado en la primera década del siglo XXI, aunque no se sabe si esta inflexión es un simple paréntesis en la tendencia señalada. 
Entre las medidas encaminadas a mejorar la cantidad y calidad de los recursos hídricos son fundamentales el uso eficiente del agua y la depuración de aguas y vertidos. El uso eficiente del agua debe concretarse de manera especial en la modernización de los sistemas de riego, en la mejora de las redes de conducción de agua y en la racionalización del consumo urbano. En España hay medidas encaminadas a ello (Plan Nacional de Regadío, mejora en la gestión urbana del agua de diferentes ciudades), pero sin duda conviene generalizar estas medidas a todo el país y ejecutarlas lo más rápidamente posible. La depuración de aguas y vertidos se contempla en el Plan Nacional de Saneamiento y Depuración, y es potenciada por normas e inversiones europeas en nuestro país. Su efectividad todavía se incrementa con la reutilización de esas aguas depuradas.

Además del uso eficiente del agua, la depuración, etc., el tránsito hacia el buen estado ecológico de las masas de agua debe apoyarse en la protección o conservación de los sistemas naturales en buen estado y la restauración o rehabilitación de los que están sensiblemente alterados.

A partir de Ramsar y el Plan Estratégico Español para la Conservación y Uso racional de los Humedales se ha avanzado significativamente en la conservación de humedales lacustres y palustres. Por el contrario, en los cursos fluviales las fuertes presiones han dificultado la aplicación de mecanismos de conservación. Se ha reconocido la gran cantidad de espacios fluviales de marcado valor paisajístico y medioambiental, por ejemplo, a través de los LICs, pero no se han llevado a cabo medidas de conservación efectivas.

Recogiendo la propuesta de la Directiva Marco de conservar las masas de agua en buen estado ecológico, la ley 11/2005 que modifica la ley del Plan Hidrológico puede significar un cambio importante en la conservación de tramos fluviales que puedan actuar de referentes dado su buen estado hidrogeomorfológico, la ausencia de presiones humanas, el adecuado estado físico-químico de las aguas y el bajo nivel de alteración de las comunidades biológicas del curso fluvial. La selección de estos tramos fluviales, a los que se concedería la calificación de Reservas Naturales Fluviales, se encargó al Área de Ingeniería Ambiental del CEDEX, que elaboró la propuesta del Catálogo Nacional de Reservas Fluviales, incluyendo 357 Reservas Fluviales y 98 Paisajes Fluviales. Este catálogo se encuentra ahora en revisión por las Confederaciones para decidir su inclusión en los Planes de Cuenca. En nuestra opinión, sería muy beneficioso que se llevasen a la práctica la declaración de gran parte de estas Reservas Fluviales y las correspondientes medidas de protección y conservación.

Hay propuestas como la de los territorios fluviales o espacios de movilidad fluvial que pretenden dar continuidad longitudinal y conectividad transversal y vertical a los sistemas fluviales. Implican devolver al río parte de su espacio mediante la limitación de usos y retirada de defensas. Aunque esta propuesta se ha hecho efectiva en otros países europeos, no se ha materializado en España. Esta propuesta conecta con el Proyecto LINDE de delimitación del Dominio Público Hidráulico, sólo ejecutada en un reducido número de cursos fluviales.

Donde el deterioro de las masas de agua y los ecosistemas hídricos es mayor, sería necesario plantear medidas de restauración, si bien allí donde las presiones son muy fuertes y numerosas sólo puede aspirarse a medidas de rehabilitación o a la protección de espacios reducidos. De nuevo, los éxitos en restauración están ligados a humedales (albuferas y lagunas costeras, lagos y lagunas endorreicas, cauces fluviales desconectados, manantiales y salinas) pero no se han aplicado auténticas restauraciones, en el sentido estricto y completo de este término en ríos. La restauración debe lograr naturalidad, funcionalidad, dinamismo, complejidad y diversidad, no belleza ni recreo ni estabilidad, ni simplemente cumplir con la legalidad. Para que se generalicen los procesos de restauración en ríos es necesario que la voluntad política y las prestaciones económicas se unan a la mentalidad de valoración y protección ambiental. 
La auténtica restauración fluvial debería tener carácter de auto-restauración hidrogeomorfológica, requiriendo caudales naturales que incluyen crecidas, movilización de sedimentos, disponibilidad de territorio fluvial, eliminación de obstáculos artificiales y margen temporal. Ésta es casi imposible por la gran cantidad de afecciones, algunas irreversibles que sufren los ríos, la enorme complejidad de los sistemas fluviales y difusión-arraigo social de un estereotipo de restauración muy alejado del resultado final de la auto-restauración. Así pues, se ejecutan acciones de estabilización de orillas, plantaciones de chopos, ajardinamiento y urbanización de márgenes, maquillaje de dragados o escolleras, etc. pero casi ni se plantean la prohibición de dragados, la apertura o derribo de presas para recuperar la naturalidad del flujo de los caudales, la limitación o desaparición de usos en el Dominio Público Hidráulico o en una sección considerable del territorio fluvial.

En 2006 el Ministerio de Medio Ambiente lanzó la Estrategia Nacional de Restauración de Ríos. Tras múltiples reuniones, elaboración de una guía metodológica, creación de voluntariado, redacción de un boletín divulgativo, la Estrategia ha logrado sensibilizar sobre la necesidad de recuperar los ríos. Pero la puesta en marcha de algunos de los proyectos de restauración que incluye no acaba de recoger el auténtico espíritu de la restauración fluvial. Mientras, desde 2009 el Centro Ibérico de Restauración Fluvial (CIREF) intenta difundir los valores de los sistemas fluviales y la necesidad de que sobre ellos se ejecuten medidas de conservación y de auténtica auto-restauración hidrogeomorfológica.

En el futuro es necesario prestar máxima atención y seguimiento a las variaciones en la disponibilidad del recurso agua que pueden asociarse al Cambio Global, así como a las repercusiones que dichas variaciones, de cantidad y distribución temporal, puedan tener en el estado ecológico de las masas de agua.

\section{Referencias}

BALAIRÓN, L. (2004): «El cambio climático y el agua», en MARTÍNEZ-VAL, J.M.: Agua y desarrollo sostenible: vida, medio ambiente y sociedad. Fundación Iberdrola. Madrid, pp. 113-143.

BERASTEGI, A.; CALVO, A.; DÍEZ, J.R.; ELSO, J.; GARCÍA, E.; GARCÍA DE JALÓN, D.; GUIBERT, M.; HERNÁNDEZ, L.; HERRERA, A.; IBARROLA, I.; JASO, C.; MAGDALENO, F.; MARTÍNEZ CAPEL, F.; MARTÍNEZ ROMERO, R.; MENDOZA, F.; OLLERO, A.; ORDEIX, M.; SANZ, F.J.; SEGURA, R.; SIMON, P.; SOROLLA, A.; URRA, F. y VERDIER, J. (2008): Biodiversidad y restauración de ecosistemas fluviales. Gestión Ambiental, Viveros y Repoblaciones de Navarra, Pamplona, 65 pp.

BISWAS, A.K. y TORTAJADA, C. (2009): «Cambiar el paisaje global de la gestión del agua», en La gestión del agua más allá del año 2020, Centro Internacional del Agua y Medio Ambiente, Instituto Aragonés del Agua, Gobierno de Aragón, Zaragoza, pp. 17-62.

CÁNCER, L.A.; LAMPRE, F. y OLLERO, A. (2001): «Glaciares actuales del Pirineo español: catálogo de masas y aproximación hidrológica», en Treballs de la Societat Catalana de Geografía, $\mathrm{n}^{\circ}$ 52, pp. 165-193.

CÁNCER, L.A.; LAMPRE, F.; OLLERO, A.; DEL VALLE, J.; SÁNCHEZ FABRE, M. et CUCHÍ, J.A. (2001): «La fusion glaciaire sur les glaciers de l'Infiernos et de la Maladeta (Pyrénées, Espagne) entre 1998 et 2000: quelques résultats dans le domaine de l'environnement», en $L a$ Houille Blanche, $\mathrm{n}^{\circ}$ 6-7/2001, pp. 83-91.

CANICIO, A.; FERRER, S.; IBÁÑEZ, C. y RIPOLL, I. (2005): Gestión y restauración de humedales. Fundación Santander Central Hispano, Madrid.

CHUECA, J. y JULIÁN, A. (2002): Los glaciares pirenaicos aragoneses: estudio de su evolución desde el final de la Pequeña Edad del Hielo hasta la actualidad a través de documentación fotográfica. Diputación de Huesca, Huesca, 323 pp.

CHUECA, J.; JULIÁN, A. \& LÓPEZ-MORENO, J.I. (2007): «Recent evolution (1981-2005) of the Maladeta glaciers, Pyrenees, Spain: extent and volume losses and their relation with climatic and topographic factors», en Journal of Glaciology, ${ }^{\circ}$ 53, pp. 547-557. 
DIMAS, M.; ESTRELA, T.; ORDIÉREZ, P. y KRINNER, W. (2004): Las aguas continentales en la Unión Europea. Ministerio de Medio Ambiente, Madrid, 390 pp.

ELLIOT, R. (1982): «Faking Nature», en Inquiry, n 25, pp. 81-93.

ESTRELA, T. (coord., 2004): Júcar Pilot River Basin, Provisional Article 5. Report Pursuant to the Water Framework Directive. Confederación Hidrográfica del Júcar, Ministerio de Medio Ambiente, Valencia, 208 pp.

GÓMEZ OREA, D. (2004): Recuperación de espacios degradados. Mundiprensa, Madrid, 582 pp.

GONZÁLEZ DEL TÁNAGO, M. y GARCÍA DE JALÓN, D. (2007): Restauración de ríos. Guía metodológica para la elaboración de proyectos. Ministerio de Medio Ambiente, Madrid, 318 pp.

GONZÁLEZ DEL TÁNAGO, M., GARCÍA DE JALÓN, D., LARA, F. y GARILLETI, R. (2006): «Indice RQI para la valoración de las riberas fluviales en el contexto de la Directiva Marco del Agua», en Ingeniería Civil, $\mathrm{n}^{\circ}$ 143, pp. 97-108.

KATZ, E. (2003): «La gran mentira: la restauración humana de la naturaleza», en KWIATKOWSKA, T. e ISSA, J. (Coords.): Los caminos de la ética ambiental, vol. II, Plaza y Valdés, México, pp. 233-244.

MARTÍNEZ GIL, F.J. (1992): Agua y medio ambiente. Justicia de Aragón, Gobierno de Aragón. Zaragoza, $171 \mathrm{pp}$.

MINISTERIO DE MEDIO AMBIENTE (2000): Libro blanco del agua en España. Secretaría de Estado de Aguas y Costas. Dirección General de Obras Hidráulicas y Calidad de las Aguas. Ministerio de Medio Ambiente, Madrid, 637 p.

MONTES, C.; RENDÓN, M.; VARELA, L. y CAPPA, M.J. (2007): Manual de restauración de humedales mediterráneos. Consejería de Medio Ambiente, Junta de Andalucía, Sevilla, 233 pp.

MUNNÉ, A., SOLÀ, C. y PRAT, N. (1998): «QBR: un índice rápido para la evaluación de la calidad de los ecosistemas de ribera», en Tecnología del agua, n 175, pp. 20-37.

NOMBELA, C.; DE LA ROSA, M.C. y MOSSO, M.A. (2004): «Agua y salud: enfermedades, potabilización», en MARTÍNEZ-VAL, J.M.: Agua y desarrollo sostenible: vida, medio ambiente y sociedad. Fundación Iberdrola. Madrid, pp. 57-85.

OLLERO, A. (2007): Territorio fluvial. Diagnóstico y propuesta para la gestión ambiental y de riesgos en el Ebro y los cursos bajos de sus afluentes. Bakeaz y Fundación Nueva Cultura del Agua, Bilbao, 255 pp.

OLLERO, A. (2008): «Alteraciones geomorfológicas de los ríos en Europa y principios para la restauración de su dinámica», en GONZÁLEZ DEL TÁNAGO, M. (coord.): Ríos y sostenibilidad. Semana temática «Agua para la vida». Tribuna del Agua, Exposición Internacional de Zaragoza.

OLLERO, A. \& ELSO, J. (2007): «The need for a «fluvial territory» or «room for the river»: living with floods by acceptance of their functions», en BAKER, C. \& VAN EIJK, P. (Eds.): Sustainable flood management: obstacles challenges and solutions, Interreg IIIC Network FLAPP, Maastricht, pp. 59-63.

OLLERO, A., BALlARÍN, D., DÍAZ BEA, E., MORA, D., SÁNCHEZ FABRE, M., ACÍN, V., ECHEVERRÍA, M.T., GRANADO, D., IBISATE, A., SÁNCHEZ GIL, L. y SÁNCHEZ GIL, N. (2007): «Un índice hidrogeomorfológico (IHG) para la evaluación del estado ecológico de sistemas fluviales», en Geographicalia, n ${ }^{\circ}$ 2, pp. 113-141.

PARDO, I., ÁlVAREZ, M., CASAS, J., MORENO, J.L., VIVAS, S., BONADA, N., ALBA-TERCEDOR, J., JÁIMEZ-CUÉLLAR, P., MOYÀ, G., PRAT, N., ROBLES, S., SUÁREZ, M.L., TORO, M. y VIDAL-ABARCA, M.R. (2002): «El hábitat de los ríos mediterráneos. Diseño de un índice de diversidad de hábitat», en Limnetica, no 21(3-4), pp. 115-133.

PRAT, N. (2004): «El agua en los ecosistemas: motor y sustancia de la vida», en MARTÍNEZ-VAL, J.M.: Agua y desarrollo sostenible: vida, medio ambiente y sociedad. Fundación Iberdrola. Madrid, pp. 41-56.

PRATS, D. y MELGAREJO, J. (2006): Desalación y reutilización de aguas. Situación en la provincia de Alicante. Confederación empresarial de la provicia de Alicante - Instituto Universitario de Agua y Ciencias Ambientales - Generalitat Valenciana. 164 p. + CD. Alicante.

PULIDO, A. y MOLINA, L. (2006): El agua y el medio ambiente. Instituto de Estudios Almerienses. Almería, $357 \mathrm{pp}$.

RODRÍGUEZ, H. (2001): «El agua: uso, calidad y gestión», en II Foro sobre Desarrollo y Medio Ambiente. Fundación MonteLeón. Obra social de Caja España. León, 294 pp. 
SOAR, P.J. \& THORNE, C.R. (2001): Channel restoration design for meandering rivers. Engineer Research and Development Center. U.S.Army Corps of Engineers, Washington, 416 pp. + appendix.

SUÁREZ, M.L. y VIDAL-ABARCA, M.R. (2008): «Índice para valorar el estado de conservación de las ramblas mediterráneas (Índice de Alteración de Ramblas ó IAR)», en Tecnología del Agua, $n^{\circ} 293$, pp. 67-78.

TAKAHASHI, K. (2009): «En busca de una aproximación completa a la getión sostenible de los recursos hídricos en la comunidad mundial», en La gestión del agua más allá del año 2020, Centro Internacional del Agua y Medio Ambiente, Instituto Aragonés del Agua, Gobierno de Aragón, Zaragoza, pp. 169-197.

TORTAJADA, C. (2007): El agua y el medio ambiente en las conferencias mundiales de las Naciones Unidas. Agenda 21, Ayuntamiento de Zaragoza, $91 \mathrm{pp}$.

UNIÓN EUROPEA (2000): Directiva Marco del Agua 2000/60/CE del Parlamento Europeo y del Consejo de la Unión Europea, de 23 de octubre de 2000. Diario Oficial de las Comunidades Europeas (22/12/2000), L327/1 - L327/71.

VILLANUEVA, A. y SÁINZ, J.A. (2008): Agua. La situación del agua en España. Recursos, gestión y tendencias. Colección EOI Medio Ambiente, Fundación EOI (Escuela de Negocios), Madrid, $128 \mathrm{pp}$. 
